\title{
Assessment of Regional Vulnerability to Natural Hazards in China Using a DEA Model
}

\author{
Jianyi Huang*, Yi Liu, and Li Ma \\ Institute of Geographic Sciences and Natural Resource Research, Key Laboratory of Regional Sustainable Development Modeling, \\ Chinese Academy of Sciences, Beijing 100101, China \\ Graduate School of the Chinese Academy of Sciences, Beijing 100049, China
}

\begin{abstract}
This paper presents a new method for quantifying regional vulnerability to natural hazards in China. In recent decades, the study of vulnerability has gained a position of centrality in natural hazards research. How to quantitatively assess vulnerability has raised much interest in academia. Researchers have proposed a variety of methods for quantitative assessment. But these methods are very sensitive to weights set for subindices. As a result, analytic results are often less convincing. A model based on data envelopment analysis (DEA) is used for the assessment of regional vulnerability to natural hazards in an attempt to improve existing analytical methods. Using a regional natural disaster system framework, this article constructs an input-output DEA model for the assessment of regional vulnerability, and takes China's mainland as a case study area. The result shows that the overall level of vulnerability to natural hazards in mainland China is high. The geographical pattern is that vulnerability is highest in western China, followed by diminishing vulnerability in central China, and lowest vulnerability levels in eastern China. There is a negative correlation between the level of regional vulnerability and level of regional economic development. Generally speaking, the more economically developed a region, the lower its regional vulnerability.
\end{abstract}

Keywords DEA model, geographical pattern, natural hazards, regional vulnerability

\section{Introduction}

Steady global environmental and climate changes produce natural disasters that have become an increasingly serious threat to the sustainable development of regional socioeconomic systems (Kates et al. 2001). Current natural hazards research has attracted great attention internationally, although scholars have long been concerned with natural hazards (Montz and Tobin 2010). Early studies were mainly descriptive and placed blame for catastrophes firmly on nature rather than on human endeavors, which can be seen as a form of

\footnotetext{
* Corresponding author. E-mail: huangjy.09b@igsnrr.ac.cn
}

"hazards determinism." Because such studies on physical processes can only explain what populations or areas may be exposed, this research was not sufficient to understand the degree to which people at a location are threatened by hazard exposure. Natural hazards may produce significantly different impacts on people and places, often depending not only on the severity of the hazards, but also on their biophysical attributes and the socioeconomic characteristics of a locale. As a response to the deficiencies in early studies, scholars proposed a new concept of vulnerability to address natural hazards related issues, which can be dated back to the landmark work of Gilbert White, Human Adjustment to Floods (White 1945).

Currently, the study of vulnerability is increasingly gathering momentum, and the concept of vulnerability is used in many fields and at different spatial levels. However the term varies among disciplines and research areas (Liverman and O'Brien 1991; Watts and Bohle 1993; Dow and Downing 1995; Cutter 1996; Fraser et al. 2006; Janssen et al. 2006; Metzger et al. 2006). Despite differences in the conceptualization of the term "vulnerability," three main perspectives have emerged (Adger 2006). The first major research theme treats vulnerability as a preexisting condition and focuses on potential exposure to hazards (Cutter 1996). Studies conducted in accordance with this perspective tend to assess the distribution of a hazardous condition, the nature of human occupancy in the hazard zone, and the degree of loss of life and property resulting from a particular event. The second major perspective on vulnerability suggests that not all individuals and groups exposed to a hazard are equally vulnerable. Rather, affected people display patterns of differential loss. In addition to exposure to a stress or crisis, this differential vulnerability also depends on the coping ability of the individuals and communities affected. Studies that follow the second approach assess the social vulnerability of impacted populations. People living at the margins, such as those without access to social services or political power, are more vulnerable than those with better access to resources. The third major theme takes the concept of vulnerability as a "hazard of place," which combines elements of the first two 
perspectives. The vulnerability of places framework treats vulnerability as a social response to a biophysical danger within a specific geographic domain, which is in accordance with the theory of regional natural hazards system (Shi 1996).

This article adopts the vulnerability of places approach in which the concept of regional vulnerability is used to measure capacity to withstand natural hazards in different regions with distinctive economies (Timmerman 1981; Turner II 2010). Specifically, vulnerability is the characteristic of a region to be wounded and has little capability to cope (defined as the ability to absorb the damaging impacts of a hazard and continue functioning), without the consideration of resilience (the ability to recover rapidly from disaster). In short, with the same severity of natural hazards and exposure of regional socioeconomic systems, regions that suffer more disaster loss have higher levels of vulnerability. In this research, vulnerability is a reflection of the degree to which a certain regional socioeconomic system might be destroyed more readily by natural hazards.

As one of the worst natural hazards inflicted countries in the world, China has frequently suffered the ravages of natural disasters. According to government statistics during the 19 years from 1990 to 2008 , on annual average, natural disasters affected about 300 million people, destroyed more than three million buildings, and forced the evacuation of more than nine million people. The direct financial losses exceeded 200 billion Yuan (Information Office of the State Council of the People's Republic of China 2009). Floods in the Yangtze, Songhua, and Nen river valleys in 1998, serious droughts in Sichuan Province and Chongqing Municipality in 2006, devastating floods in the Huai River valley in 2007, extreme cold weather and sleet in south China in early 2008, and the earthquake that shook Sichuan, Gansu, Shaanxi, and other places on 12 May 2008 all caused tremendous losses. Study of China's regional vulnerability to natural hazards can provide benefits if such research leads to the adoption of effective strategies for future disaster mitigation. Although the concept of vulnerability has been applied in many research fields, vulnerability assessment remains a difficult task. Researchers have struggled to find suitable frameworks and metrics for vulnerability assessment (Blaikie, Cannon, and Davis 1994; Klein and Nicholls 1999; Cutter, Boruff, and Shirley 2003; Cutter and Finch 2008; Boruff, Emrich, and Cutter 2005). The methods adopted by most current researchers are to establish an index of vulnerability based on complicated proxy data sets that indicate vulnerability. These methods provide useful tools for identifying and monitoring vulnerability over time and space, as well as introduce a way to understand the processes underlying vulnerability.

But, this type of research has generated additional questions. The first question relates to the choice of proxies for vulnerability assessment. Because of the complexities involved in the concept of vulnerability, researchers use different proxies to indicate vulnerability. The second issue relates to the relative contributions of the variables used to define vulnerability. Some researchers choose not to weigh variables differentially to allow for dissimilar effects (Cutter, Mitchell, and Scott 2000), while others have explored distinctive weighting schemes designed to reflect variations in importance (Brooks, Adger, and Kelly 2005; Lazarus 2010). Most methods used for calculating weights are more or less subjective, which reduces confidence in the results. Thus determining appropriate weighting is challenging for this type of methods of vulnerability assessment (Lazarus 2010).

Taking a different approach, a model based on a data envelopment analysis (DEA) is proposed in an attempt to improve upon traditional methods because the DEA approach does not require determining weight parameters. In recent years, DEA modeling has been used to evaluate the performance of various entities engaged in different activities in varied contexts, including benchmarking in health care (hospitals, doctors), education (schools, universities), banks, manufacturing, and management evaluation (Anderson 2002). But only limited DEA research in the field of natural disasters has occurred, although some researchers have begun to use DEA models to carry out preliminary studies (Wei et al. 2004; Zou and Wei 2009). There are some shortcomings in these studies, including relatively simplistic selection of indicators for assessment and inadequate consideration of the regional physical context of natural hazards. This article first discusses the applicability of DEA modeling to natural hazard vulnerability assessment. It then constructs indices that are used for regional vulnerability assessment based on a natural disaster system framework. Finally, an analytical model is developed. Based on the annual data of governmental statistics from 2001 to 2008 (National Bureau of Statistics of China 20012008; Department of Finance and Administration, Ministry of Civil Affairs of China 2001-2008), regional vulnerabilities in China's mainland area are assessed as a case study.

\section{Methods}

\subsection{Introduction of the DEA Model}

Data envelopment analysis is a relatively new, data-oriented approach for evaluating the performance of a set of peer entities, called Decision Making Units $(D M U s)$, which converts multiple inputs into multiple outputs. Because DEA requires very few assumptions, in their original study Charnes, Cooper, and Rhodes (1978) described DEA as a mathematical programming model applied to observational data that provides a new way of obtaining empirical estimates of relations - such as production functions and/or efficient production possibility surfaces. Formally, DEA is a methodology directed to frontiers rather than central tendencies. Instead of trying to fit a regression plane through the center of the data as in statistical regression, for example, one "floats" a piecewise linear surface to rest on top of the observations (Cooper, Seiford, and Zhu 2004). Because of this characteristic, DEA 
proves particularly adept at uncovering relationships that remain hidden from other methodologies.

Based on the concept of relative efficiency, researchers take a DEA model as an excellent and easily used methodology for modeling operational processes for performance evaluations. DEA model is a useful tool for the efficiency evaluation of an "input-output" system. In the context of natural disasters, the occurrence of loss from natural disasters represents the product of interactions within regional natural disaster system, which can be seen as an "input-output" system. Specifically, disaster losses (as output factors) are the products of interactions within the regional natural disaster system whose input factors include hazards, disaster formative environment, and exposure units (Shi 1996). Hazards are the physical processes of the earth system that threaten human society. Disaster formative environment is the conditions of the physical environment that aggravate or decrease the effects of hazards, such as slope, elevation, soil, and vegetation. Exposure units mainly include all types of human activities.

For example, flood as a hazard is dangerous only when a locale is near a river or has a low elevation, which can be seen as the action of the disaster formative environment. Hazard and disaster formative environment are only external conditions for disaster losses - the hazard danger is relative to human socioeconomic activities in a flood-prone place. These regional human activities are the internal reason for disaster losses. A place devoid of human activity is not in danger, so the role of human activity is to create exposure units that experience damage in a flood. While human activities and structures constitute components that are the prerequisite for disaster losses, only the vulnerable locale will suffer loss. This variable vulnerability is a hidden characteristic of regional human activity, which is simply reflected in the differential severity of the disaster loss sustained by different areas under the same natural hazards scenario. We conclude that disaster losses are the synergic action of regional natural disaster systems. In the face of natural disasters, people would hope for less loss from the disasters. But the normal DEA model expects more losses (products) with the same level of flood (input). This appears in conflict with the goal of actual disaster impact reduction in most management situations.
Seen from the process of disasters, the essence of relative efficiency is similar to regional vulnerability. More generally, regional vulnerability to natural hazards is reflected in the production efficiency of loss caused by natural disasters. Usually a region with higher vulnerability, under the same level of natural hazard impact, will suffer more severe damage. That is, the operational efficiency of the regional natural disaster system is high. While on the other hand, for regions with low vulnerability, because of the low efficiency in generating damages, the loss caused by natural disasters is usually relatively light. This article uses relative efficiency calculated by a DEA model to reflect regional vulnerability to natural hazards (Figure 1).

Since the DEA method was developed, various DEA models have been proposed. In this article, the classical C2R model is adopted for analysis. Because the main purpose of our work is the application of the DEA model, we only make a simple introduction of the model; detailed description and calculations can be found in related work (Coelli 1996). The model assumes that there are $\mathrm{n}$ decision-making units, $D M U_{j}(j=1,2, \cdots, \mathrm{n})$ (the region unit for vulnerability assessment); each $D M U_{j}$ has $\mathrm{m}$ inputs and $\mathrm{s}$ outputs. The input vector can be written as $X_{j}=\left(x_{1 j}, x_{2 j}, \cdots, x_{\mathrm{mj}}\right)^{T}$, while the output vector is $Y_{j}=\left(y_{1 j}, y_{2 j}, \cdots, y_{\mathrm{s} j}\right)^{T}$. So the C2R model for the assessment of regional vulnerability to natural hazard is as follows:

$$
\left(\begin{array}{l}
\min \left[\theta-\varepsilon\left(\hat{e}^{T} S^{-}+e^{T} S^{+}\right)\right] \\
\text {s.t. } \sum_{j=1}^{n} X_{j} \lambda_{j}+S^{-}=\theta X_{0} \\
\sum_{j=1}^{n} Y_{j} \lambda_{j}-S^{+}=Y_{0} \\
\lambda_{j} \geq 0, X_{j} \geq 0, Y_{j} \geq 0, j=1,2, \cdots, n \\
S^{-} \geq 0, S^{+} \geq 0 \\
\hat{e}^{T}=(1,1, \cdots, 1) \in E_{m}, e^{T}=(1,1, \cdots, 1) \in E_{n}
\end{array}\right.
$$

Where $\theta(0<\theta \leq 1)$ is total economic efficiency, $\lambda_{j}$ is weight variable; $S^{-}$is a slack variable, $S^{+}$is the remnant variable; $\varepsilon$ is non-Archimedean infinitesimal, generally taking $\varepsilon=10^{-6}$. If the $\theta$ score of one $D M U$ is close to 1 , it indicates that this

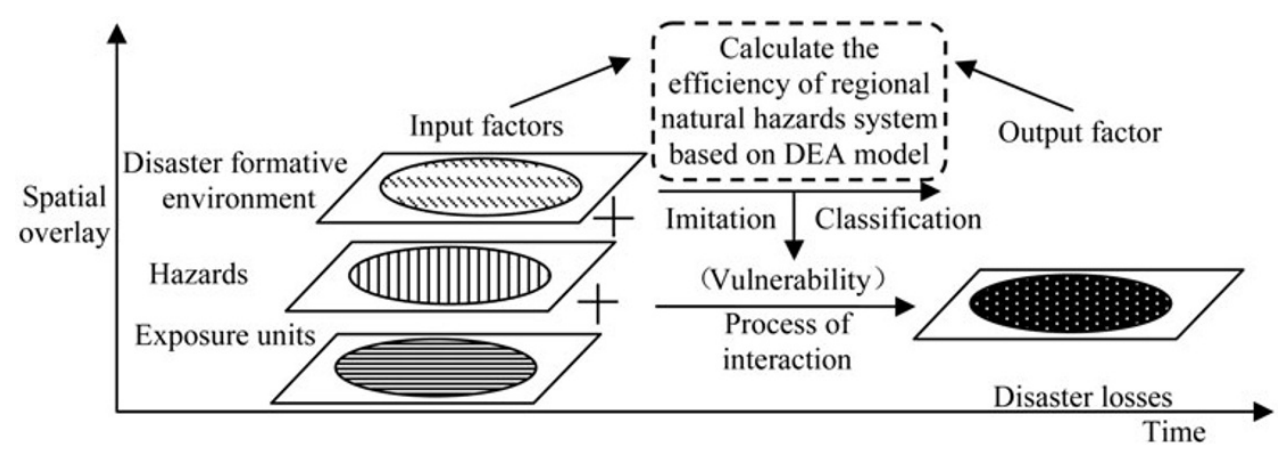

Figure 1. Framework for the assessment of regional vulnerability to natural hazards based on a DEA model 
unit has a high input-output ratio, namely high efficiency for production. In the case of natural hazards, it can be considered that the region has a higher potential to be harmed. In other words, it has a higher vulnerability. A lower $\theta$ score implies that the region concerned has relatively low vulnerability. When $\theta=1$, the ratio of input to output is at the optimal production frontier, so the production efficiency of the region reaches the maximum. That is, the damage caused by natural disasters is maximized and regional vulnerability to natural hazards is the highest.

\subsection{Index Construction and Data Processing}

As discussed above, disaster loss is the synergic action of the regional natural disaster system. Each element of the system plays a different role in the process of natural disasters. The combined effect of the hazard and disaster formative environment is seen as a threat or danger; while exposure units such as properties, buildings, and people take on the characteristics of regional socioeconomic systems. Only the simultaneous action of the two aspects will induce disaster losses. Specifically, the regional natural hazards system can be seen as negative "production activities;" the "input" factors include the danger of the natural hazards, namely the combination of the magnitude and frequency of regional natural hazards and the conditions of natural environment, such as elevation, slope, geological conditions, vegetation, and so on, as well as the exposure of the socioeconomic system, such as the area planted with crops, total population size, level of economic activity, existing infrastructure, and similar variables. The "output" elements are the disaster losses, such as the size of the affected area, number of people impacted, scale of economic losses, and extent of casualties. Efficiency can be taken as a reflection of vulnerability. The higher the efficiency, the higher the vulnerability of the region. So this research builds the input and output factors for the DEA model of regional natural hazards from three aspects: (1) the danger of regional hazards $(D I)$, an input factor; (2) the exposure of the regional socioeconomic system $(E I)$, an input factor; and (3) the regional natural disaster losses $(L I)$, an output factor. The efficiency calculated by the DEA model can be used as a surrogate by which to assess regional vulnerability to natural hazards. There have been many debates about the deficiencies of the DEA model, because the results differ depending on the selection of model variables. It is therefore very important to make a good choice of the variables. Considering the availability and representativeness of data, we made a selection of the following indicators for each index (Table 1), and identified 31 basic assessment units, including 22 provinces, 5 autonomous regions, and 4 municipalities of mainland China.

In order to make a quantitative assessment of the danger of natural hazards, this article takes as a point of departure the research work of Ma (1994), which makes a quantitative assessment of the danger posed by various natural hazards. Because disaster losses fluctuate greatly over the years, single year disaster loss data are unsuitable for vulnerability analysis. We use the average of disaster losses over multiple years (2001-2008) instead. Correspondingly, in order to keep consistency between the model input and output, we also take the average value of indicators of exposure of regional socioeconomic system (Table 1) for analysis.

Although DEA model can be used to assess the relative efficiency of the $D M U s$ with multiple inputs and outputs, the number of the inputs and outputs is not unlimited. There is an important rule of thumb that the number of $D M U s$ must be no less than the number of inputs and outputs, and the variables must have low correlation, or the capacity of DEA model to calculate efficiency will be reduced (Anderson 2002). So it is better to reduce the number of inputs and outputs when the

Table 1. Indicator system and data for vulnerability assessment

\begin{tabular}{|c|c|c|c|c|}
\hline & Description of Index & Indicator Selection & Data Processing & Data Source \\
\hline $\begin{array}{l}\text { Danger of regional } \\
\text { hazards }(D I)\end{array}$ & $\begin{array}{l}\text { The reflection of the comprehensive } \\
\text { action of hazards and disaster formative } \\
\text { environment, decided by the magnitude } \\
\text { and frequency of regional natural hazards } \\
\text { and natural environmental conditions. }\end{array}$ & $\begin{array}{l}\text { The five main types of natural hazards } \\
\text { in China, including earthquake; } \\
\text { meteorological hazards such as hail, } \\
\text { frost, sandstorm; drought; flood; and } \\
\text { geological hazards. }\end{array}$ & $\begin{array}{l}\text { Calculate the mean value } \\
\text { of the danger score of } \\
\text { natural hazards, used as } \\
\text { the DEA model input. }\end{array}$ & Мa 1994 \\
\hline $\begin{array}{l}\text { Exposure of regional } \\
\text { socioeconomic } \\
\text { system }(E I)\end{array}$ & $\begin{array}{l}\text { The assessment of lives and property } \\
\text { threatened by natural disasters in the } \\
\text { region. Usually the higher the degree of } \\
\text { exposure, the greater the potential losses. }\end{array}$ & $\begin{array}{l}\text { Regional total population, GDP, per } \\
\text { capita GDP, population density, } \\
\text { cultivated areas, GDP km², regional } \\
\text { urbanization level. }\end{array}$ & $\begin{array}{l}\text { Factor analysis, taking } \\
\text { the extracted principal } \\
\text { components as the DEA } \\
\text { model input. }\end{array}$ & $\begin{array}{l}\text { National Bureau } \\
\text { of Statistics of } \\
\text { China 2001-2008 }\end{array}$ \\
\hline $\begin{array}{l}\text { Regional natural } \\
\text { disaster losses }(L I)\end{array}$ & $\begin{array}{l}\text { The assessment of regional losses caused } \\
\text { by natural disasters, such as casualties, } \\
\text { crop yield reduction or total loss of } \\
\text { harvest, building damage, and other } \\
\text { losses. }\end{array}$ & $\begin{array}{l}\text { Disaster affected area, area with total } \\
\text { loss of harvest, proportion of farmland } \\
\text { with total loss of harvest, affected } \\
\text { population, number of deaths from } \\
\text { disasters, population with drinking } \\
\text { water problem, number of collapsed or } \\
\text { damaged building units, direct } \\
\text { economic losses. }\end{array}$ & $\begin{array}{l}\text { Factor analysis, taking } \\
\text { the extracted principal } \\
\text { components as the DEA } \\
\text { model output. }\end{array}$ & $\begin{array}{l}\text { Department of } \\
\text { Finance and } \\
\text { Administration, } \\
\text { Ministry of Civil } \\
\text { Affairs of China } \\
\text { 2001-2008 }\end{array}$ \\
\hline
\end{tabular}

\footnotetext{
$\dagger$ The danger of natural hazards faced by any given region is the combined result of various hazards, and it is difficult to determine the weight of each hazard. So we take the average of the scores of all natural hazards as a comprehensive assessment.
} 
number of $D M U s$ is limited, although it is also important to maintain the original information represented by the input and output variables. Factor analysis is a useful tool for reducing the number of variables while minimizing the information loss of the original variables. This research uses factor analysis to process the indicators, using the extracted principal components as the input and output variables. Since the principal components extracted will have negative values that are forbidden in the DEA model, data transformation is needed. We make a linear stretch of the data to a new data range of 1 to 5 by using the minimum-maximum standardization method. The transformation is done as follows:

$$
V^{\prime}=\frac{V-\min _{A}}{\max _{A}-\min _{A}}\left(n e w_{-} \max _{A}-n e w_{-} \min _{A}\right)+n e w_{-} \min _{A}
$$

Where $V^{\prime}$ is the new data value after normalization, $V$ is the original data value, $\max _{A}$ and $\min _{A}$ represent the maximum and minimum of original data sets, while $n e w \max _{A}$ and $n e w \_\min _{A}$ are taken as the maximum and minimum values of the new data sets.

\section{Results and Analysis}

\subsection{Result of Factor Analysis}

We first perform a factor analysis of the DEA model input and output factors. Two principle factors are extracted from the indicators of exposure of regional socioeconomic system and two other principle factors are extracted from regional natural disaster losses (Table 2). From the loadings of each principal component, we can see that the principal exposure factors of the regional socioeconomic system largely describe the density (factor 1) and total amount (factor 2) characteristics of regional exposure. The principal factors of regional natural disaster losses reflect human and economic losses (factor 1) and agricultural losses (factor 2). We use these four new principle factors as the final variables of the DEA model to calculate the efficiency of each $D M U$.

\subsection{Vulnerability Assessment Based on Relative Efficiency}

After data processing, we obtained the production efficiency of natural disaster losses of the 31 DMUs using the DEAP Version 2.1 software (Table 3), which can be used for the analysis of vulnerability. The efficiency of Inner Mongolia, Heilongjiang, Fujian, Jiangxi, Hainan, Chongqing, Sichuan, Yunnan, and Ningxia all equal to1, which means that the relative production efficiency of natural disaster losses is highest in all these $D M U s$. From a vulnerability perspective, these regions have low capacity to resist natural hazards and thus have higher vulnerability. As a result, for the same natural hazards (with the same model inputs), more disaster losses are expected as compared with other regions. In fact, these regions are the typical vulnerable regions to natural hazards. For example, Fujian and Hainan are provinces that have suffered from typhoons every year, and Yunnan Province experienced a severe drought three years ago. Generally, these places often suffer great economic losses due to the disastrous consequences of these events. The three regions that have the lowest efficiency are Shanghai (0.463), Beijing (0.499), and Jiangsu (0.561). These places are the most economically and socially developed regions in mainland China, with a higher capacity to invest in disaster prevention. Even if natural disasters caused great damage to these places, compared to the huge size of the regional economy disaster losses would be relatively modest. As a consequence, these regions have a low vulnerability to natural hazards. Regional vulnerability as explained by the efficiency of DEA model is in accordance with the actual vulnerability situation in China, so this method produces a good analytical result.

Vulnerability to natural hazards has a close relationship with the physical and social environments of a region. In order to determine the key factor that causes vulnerability, a correlation analysis was carried out in this research.

Table 2. The extracted principal components based on factor analysis

\begin{tabular}{|c|c|c|c|c|c|}
\hline \multicolumn{3}{|c|}{ Exposure of Regional Socioeconomic System } & \multicolumn{3}{|c|}{ Regional Disaster Losses } \\
\hline Indicators & Factor 1 & Factor 2 & Indicators & Factor 1 & Factor 2 \\
\hline Total GDP & & 0.837 & Disaster affected area & & 0.921 \\
\hline Total population & & 0.958 & Area with total loss of harvest & & 0.963 \\
\hline Population density & 0.931 & & $\begin{array}{l}\text { Proportion of farmland with total loss of } \\
\text { harvest }\end{array}$ & & 0.736 \\
\hline GDP km-2 & 0.920 & & Affected population & 0.842 & \\
\hline Cultivated areas & & 0.675 & Number of deaths from disasters & 0.849 & \\
\hline Per capita GDP & 0.967 & & Population with drinking water problem & 0.616 & \\
\hline \multirow[t]{3}{*}{ Urbanization level } & 0.896 & & Number of collapsed building units & 0.871 & \\
\hline & & & Number of damaged building units & 0.947 & \\
\hline & & & Direct economic losses & 0.650 & \\
\hline
\end{tabular}

Note: Factor loadings smaller than 0.6 are not listed. Factors selected have greater than 1 eigenvalue and the contribution of the cumulative variance is more than 80 percent. 
Table 3. Regional vulnerability assessment for mainland China

\begin{tabular}{|c|c|c|c|c|c|c|}
\hline & \multicolumn{2}{|c|}{$E I$} & \multirow[t]{2}{*}{$D I$} & \multicolumn{2}{|l|}{$L I$} & \multirow{2}{*}{$\begin{array}{c}\text { Production Efficiency } \\
\text { of Disaster Losses }\end{array}$} \\
\hline & Density & Total Amount & & Human and Economic Losses & Agricultural Losses & \\
\hline Beijing & 3.07 & 1.64 & 3.6 & 1.25 & 1.22 & 0.499 \\
\hline Shanghai & 5.00 & 2.00 & 2.2 & 1.45 & 1.00 & 0.463 \\
\hline Jiangsu & 2.24 & 4.34 & 3.2 & 2.72 & 2.14 & 0.561 \\
\hline Guangdong & 2.34 & 4.49 & 3.6 & 3.39 & 1.94 & 0.572 \\
\hline Liaoning & 1.85 & 2.81 & 3.2 & 1.56 & 3.20 & 0.621 \\
\hline Tianjin & 2.79 & 1.40 & 3.4 & 1.17 & 1.55 & 0.639 \\
\hline Zhejiang & 2.25 & 3.07 & 3.0 & 3.25 & 1.97 & 0.673 \\
\hline Shandong & 1.93 & 5.00 & 3.6 & 3.09 & 3.56 & 0.681 \\
\hline Hebei & 1.49 & 3.75 & 3.8 & 2.28 & 3.45 & 0.719 \\
\hline Xinjiang & 1.23 & 1.95 & 2.0 & 1.99 & 1.96 & 0.772 \\
\hline Jilin & 1.46 & 2.33 & 2.4 & 1.62 & 3.32 & 0.789 \\
\hline Hubei & 1.48 & 3.12 & 3.2 & 3.59 & 2.97 & 0.806 \\
\hline Shanxi & 1.36 & 2.29 & 3.4 & 2.12 & 3.20 & 0.853 \\
\hline Gansu & 1.02 & 2.09 & 3.6 & 1.80 & 2.85 & 0.868 \\
\hline Guangxi & 1.19 & 2.61 & 3.2 & 3.74 & 2.33 & 0.894 \\
\hline Qinghai & 1.26 & 1.07 & 2.2 & 1.35 & 1.57 & 0.906 \\
\hline Anhui & 1.32 & 3.20 & 3.2 & 3.40 & 3.38 & 0.916 \\
\hline Henan & 1.38 & 4.50 & 2.8 & 3.00 & 3.83 & 0.920 \\
\hline Shaanxi & 1.26 & 2.35 & 4.0 & 3.19 & 2.75 & 0.942 \\
\hline Guizhou & 1.00 & 2.30 & 2.8 & 3.39 & 2.26 & 0.972 \\
\hline Tibet & 1.08 & 1.00 & 2.6 & 1.53 & 1.43 & 0.978 \\
\hline Inner Mongolia & 1.32 & 2.47 & 2.2 & 1.46 & 5.00 & 1.000 \\
\hline Heilongjiang & 1.33 & 3.48 & 2.0 & 1.51 & 4.49 & 1.000 \\
\hline Fujian & 1.78 & 2.26 & 3.6 & 4.12 & 1.87 & 1.000 \\
\hline Jiangxi & 1.32 & 2.34 & 2.2 & 3.62 & 2.23 & 1.000 \\
\hline Hunan & 1.37 & 3.10 & 3.2 & 5.00 & 3.02 & 1.000 \\
\hline Hainan & 1.46 & 1.18 & 3.8 & 1.54 & 2.11 & 1.000 \\
\hline Chongqing & 1.48 & 1.95 & 3.0 & 3.47 & 2.32 & 1.000 \\
\hline Sichuan & 1.19 & 3.79 & 3.6 & 4.68 & 2.64 & 1.000 \\
\hline Yunnan & 1.03 & 2.73 & 3.2 & 4.73 & 1.74 & 1.000 \\
\hline Ningxia & 1.31 & 1.15 & 2.6 & 1.00 & 2.49 & 1.000 \\
\hline
\end{tabular}

Three indicators were selected as independent variables in the correlation analysis with natural disaster losses: (1) the proportion of primary industry in GDP; (2) per capita GDP; and (3) the danger index of regional hazards (Table 4). The results show that among the three indicators the ratio of the primary industry has a predominant positive correlation with vulnerability. The reason for this correlation is the high sensitivity of the agricultural sector to the impacts of natural hazards. Per capita GDP as the representative of regional economic capacity has a significant negative relationship with vulnerability, because the more developed an area is, the higher is the level of preventative measures deployed to mitigate the impact of natural hazards. The danger index of regional hazards does not have a significant correlation with vulnerability. It is even slightly negatively related to vulnerability, which is contrary to common sense. This is because some regions in the high natural hazard danger areas may have low vulnerability due to a strong regional economic capacity. In fact, the first two variables can be taken as representatives of the socioeconomic situation, while the third variable acts largely as the deputy of the physical factors. We conclude that the social environment is the main factor affecting regional vulnerability to natural hazards. That is, disasters are not caused by natural hazards, but by the social systems that make people or regions vulnerable (Cutter 2010).

\subsection{Classification and Mapping of Vulnerability}

Based on the result of relative efficiency $(\theta)$, we divide regional vulnerability into four levels: slight $(\theta<0.6)$, medium $(0.6 \leq \theta<0.8)$, high $(0.8 \leq \theta<1.0)$, and severe $(\theta$ $=1)$. In order to illustrate the geographic patterns of regional

Table 4. Correlation between vulnerability and physical and social environment indicators

\begin{tabular}{lccc}
\hline & Proportion of Primary Industry in GDP & Per Capita GDP & Danger Index of Regional Hazards \\
\hline Pearson correlation & $-656^{* *}$ & $-.817^{* *}$ & -.145 \\
\hline
\end{tabular}

** Correlation is significant at the 0.01 level (2-tailed). 


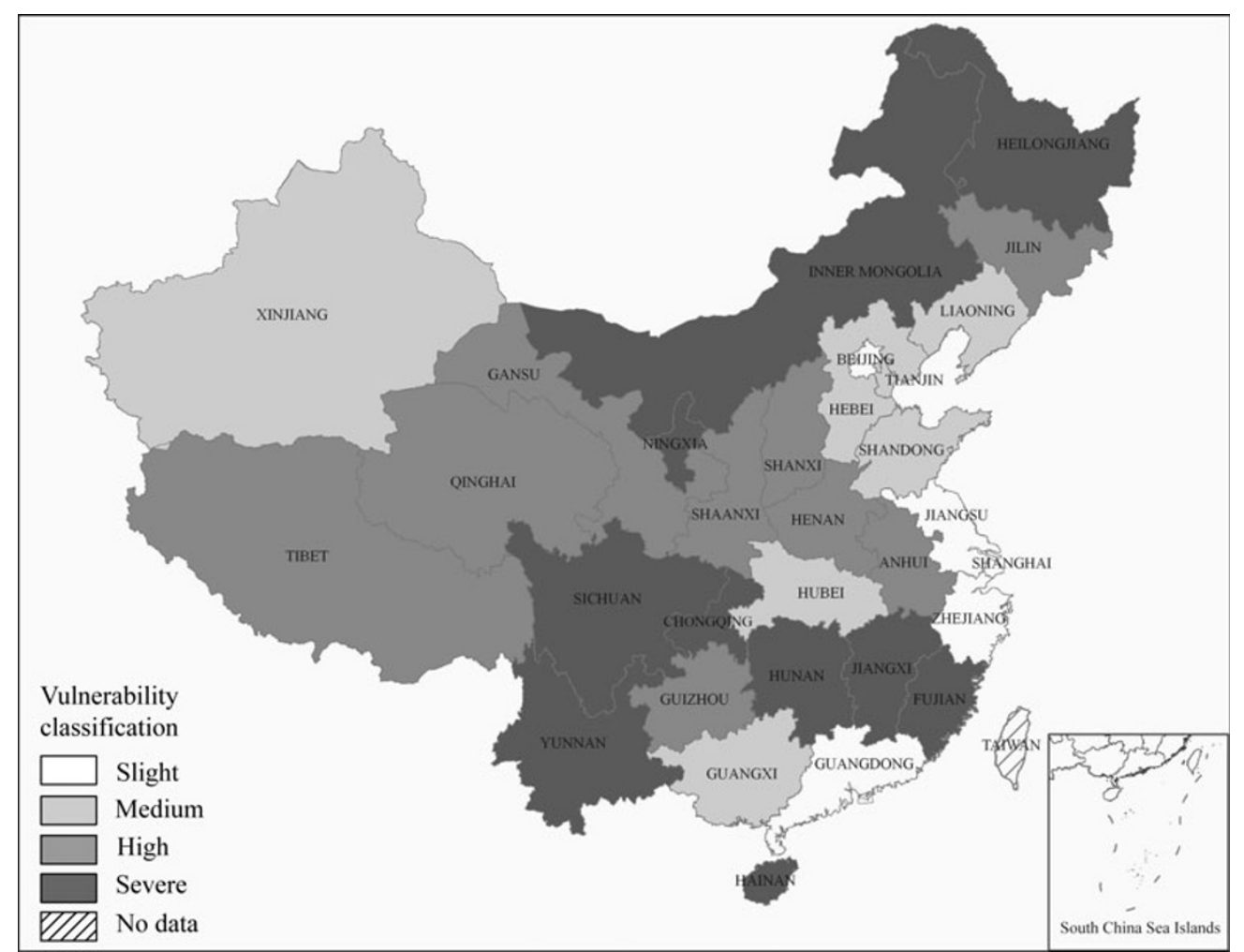

Figure 2. Spatial pattern of the regional vulnerability to natural hazards in mainland China

vulnerability to natural hazards, we drew a regional vulnerability map (Figure 2), which shows the geographic pattern of vulnerability for mainland China. Regions with slight vulnerability are concentrated in the developed eastern coastal areas of China, while regions with severe vulnerability are mainly located in the central and western areas of China. Most of the regions in central and western areas have medium or high vulnerability. So the overall vulnerability level of China decreases from west to east, which has a close relationship with the characteristics of the natural environment and the country's level of development. This result may provide some useful input to the natural hazards mitigation work of the government. In fact, the Chinese government's current policies for disaster relief are directly opposite to what this research has suggested. For disaster relief purposes, provinces in mainland China are divided into three regional groups: eastern, central, and western. Provinces in western China, though underdeveloped, receive fewer central government relief funds compared to provinces in well-developed eastern China. Relief funds distributed to provinces in central China are at an intermediate level. Our research suggests a totally different approach than current practice. For future natural hazard prevention planning, the government should increase the prevention and mitigation input into the central and western parts in order to improve regional resilience and reduce vulnerability. This would especially enhance the disaster prevention capacity of regions with severe vulnerability. Considering that China has a large and critically important agricultural sector but possesses weak and poorly resilient agricultural infrastructures, sustained efforts should be made to increase the ability of the agricultural sector to fight natural hazards.

\section{Conclusion}

Considering the deficiencies of the more often used metrics of quantitative vulnerability assessment, this research has proposed using the DEA model as a new approach to the assessment of regional vulnerability to natural hazards. In contrast to previous vulnerability assessments, which emphasize identifying suitable vulnerability indicators and constructing an overall vulnerability index from those indicators, this research has assessed vulnerability from the perspective of a regional natural disaster system. The production efficiency of natural disaster losses is taken as a reflection of vulnerability, and a new method for classifying vulnerability is also proposed. The results show that the geographical pattern of vulnerability displays a decreasing trend from western China through central China to eastern China. Compared to the physical context, social context, economic development in particular, has a much greater influence on regional vulnerability. We have found a negative correlation between the level of regional vulnerability and regional economic development level. The more economically developed a region, the lower the regional vulnerability. The structure of regional 
socioeconomic systems also has a close relationship with vulnerability; especially the proportion of primary industry in GDP has a significant positive correlation with vulnerability. These results are relevant to disaster relief policy since they suggest that the government should pay more attention to major agricultural areas of the country in the work of disaster prevention and reduction. While it would be of great practical value to analyze how the vulnerability of regions changes, due to the limitations of our data, in this study we could only make a static assessment of regional vulnerability. Studies identifying changing vulnerability through time will be pursued in our future research.

\section{Acknowledgments}

This article has received comments from three reviewers. The authors are very grateful for their important advices for the improvement of the article. This study was supported by the National Key Technology R\&D Program of China (2008BAK50B05).

\section{References}

Adger, W. N. 2006. Vulnerability. Global Environmental Change 16 (3): 268-81.

Anderson, T. 2002. A Data Envelopment Analysis (DEA) Home Page. http://www.emp.pdx.edu/dea/homedea.html\#Applications.

Blaikie, P., T. Cannon, and I. Davis. 1994. At Risk: Natural Hazards, People's Vulnerability, and Disasters. London: Routledge.

Boruff, B. J., C. Emrich, and S. L. Cutter. 2005. Erosion Hazard Vulnerability of US Coastal Counties. Journal of Coastal Research 21 (5): 932-42.

Brooks, N., W. N. Adger, and P. M. Kelly. 2005. The Determinants of Vulnerability and Adaptive Capacity at the National Level and the Implications for Adaptation. Global Environmental Change 15 (2): 151-63.

Charnes, A., W. Cooper, and E. Rhodes. 1978. Measuring the Efficiency of Decision Making Units. European Journal of Operational Research 2 (6): 429-44.

Coelli, T. 1996. A Guide to DEAP Version 2.1: A Data Envelopment Analysis (Computer) Program. Centre for Efficiency and Productivity Analysis, University of New England, Australia. http://www.uq. edu.au/economics/cepa/deap.htm.

Cooper, W. W., L. M. Seiford, and J. Zhu. 2004. Data Envelopment Analysis. In Handbook on Data Envelopment Analysis, edited by W. W. Cooper, L. M. Seiford, and J. Zhu, 1-39. Boston: Springer (Kluwer Academic Publishers).

Cutter, S. L. 1996. Vulnerability to Environmental Hazards. Progress in Human Geography 20 (4): 529-39.

- 2010. Social Science Perspectives on Hazards and Vulnerability Science. Geophysical Hazards 10 (1): 17-30.

Cutter, S. L., B. J. Boruff, and W. Shirley. 2003. Social Vulnerability to Environmental Hazards. Social Science Quarterly 84 (2): 242-61.

Cutter, S. L., and C. Finch. 2008. Temporal and Spatial Changes in Social Vulnerability to Natural Hazards. PNAS 105 (7): 2301-06.
Cutter, S. L., J. T. Mitchell, and M. S. Scott. 2000. Revealing the Vulnerability of People and Places: A Case Study of Georgetown County, South Carolina. Annals of the Association of American Geographers 90 (4): 713-37.

Department of Finance and Administration, Ministry of Civil Affairs of China. 2001-2008. China Civil Affairs's Statictical Yearbook. Beijing: China Statistics Press (in Chinese).

Dow, K., and T. E. Downing. 1995. Vulnerability Research: Where Things Stand. Human Dimensions Quarterly 1995 (1): 3-5.

Fraser, E. D. G., A. J. Dougill, W. E. Mabee, M. Reed, and P. McAlpine. 2006. Bottom up and Top Down: Analysis of Participatory Processes for Sustainability Indicator Identification as a Pathway to Community Empowerment and Sustainable Environmental Management. Journal of Environmental Management 78 (2): 114-27.

Information Office of the State Council of the People's Republic of China. 2009. China's Actions for Disaster Prevention and Reduction. http://news.xinhuanet.com/newscenter/2009-05/11/content 11351082.htm (in Chinese).

Janssen, M. A., M. L. Schoon, W. Ke, and K. Brner. 2006. Scholarly Networks on Resilience, Vulnerability and Adaptation within the Human Dimensions of Global Environmental Change. Global Environmental Change 16 (3): 240-52.

Kates, R. W., W. C. Clark, R. Corell, J. M. Hall, C. C. Jaeger, I. Lowe, J. J. McCarthy, H. J. Schellnhuber, B. Bolin, and N. M. Dickson. 2001. Sustainability Science. Science 292 (5517): 641-42.

Klein, R. J. T., and R. J. Nicholls. 1999. Assessment of Coastal Vulnerability to Climate Change. Ambio 28 (2): 182-87.

Lazarus, N. W. 2010. Coping Capacities and Rural Livelihoods: Challenges to Community Risk Management in Southern Sri Lanka. Applied Geography 31 (1): 20-34.

Liverman, D. M., and K. L. O’Brien. 1991. Global Warming and Climate Change in Mexico. Global Environmental Change 1 (5): 351-64.

Ma, Z. J. 1994. Major Disaster of China and Mitigation Measures. Beijing: Science and Technology Press (in Chinese, English summary).

Metzger, M. J., M. D. A. Rounsevell, L. Acosta-Michlik, R. Leemans, and D. Schröter. 2006. The Vulnerability of Ecosystem Services to Land Use Change. Agriculture, Ecosystems \& Environment Scenario-Based Studies of Future Land Use in Europe 114 (1): 69-85.

Montz, B. E., and G. A. Tobin. 2010. Natural Hazards: An Evolving Tradition in Applied Geography. Applied Geography 31 (1): 1-4.

National Bureau of Statistics of China. 2001-2008. China Statistical Yearbook. Beijing: China Statistics Press (in Chinese).

Shi, P. J. 1996. Theory and Practice of Disaster Study. Journal of Natural Disasters 5 (4): 6-14 (in Chinese).

Timmerman, P. 1981. Vulnerability, Resilience and the Collapse of Society: A Review of Models and Possible Climatic Applications. Toronto: Institute for Environmental Studies, University of Toronto, Canada.

Turner II, B. L. 2010. Vulnerability and Resilience: Coalescing or Paralleling Approaches for Sustainability Science? Global Environmental Change 20 (4): 570-76.

Watts, M. J., and H. G. Bohle. 1993. The Space of Vulnerability: The Causal Structure of Hunger and Famine. Progress in Human Geography 17 (1): 43-67.

Wei, Y. M., Y. Fan, C. Lu, and H. T. Tsai. 2004. The Assessment of Vulnerability to Natural Disasters in China by Using the DEA Method. Environmental Impact Assessment Review 24 (4): 427-39.

White, G. F. 1945. Human Adjustment to Floods: A Geographical Approach to the Flood Problem in the United States. Chicago: The University of Chicago, Department of Geography, Research Paper No. 29.

Zou, L. L., and Y. M. Wei. 2009. Impact Assessment Using DEA of Coastal Hazards on Social-Economy in Southeast Asia. Natural Hazards 48 (2): 167-89.

Open Access This article is distributed under the terms of the Creative Commons Attribution License which permits any use, distribution, and reproduction in any medium, provided the original author(s) and source are credited. 